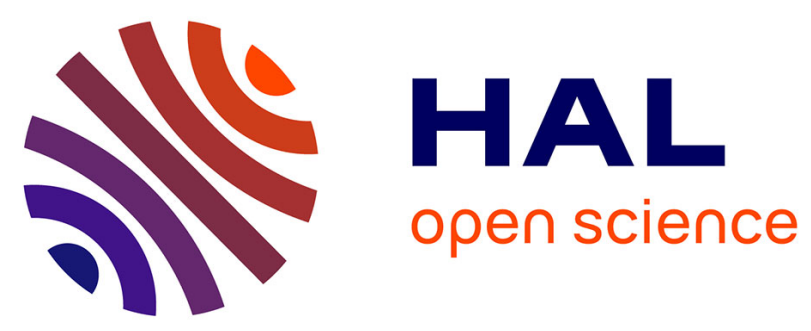

\title{
Prior suggestive symptoms in third of patients consulting for a "first" demyelinating event.
}

Olivier Gout, Christine Lebrun Frenay, Pierre Labauge, Emmanuelle Lepage, Pierre Clavelou, Sylvie Allouche

\section{- To cite this version:}

Olivier Gout, Christine Lebrun Frenay, Pierre Labauge, Emmanuelle Lepage, Pierre Clavelou, et al.. Prior suggestive symptoms in third of patients consulting for a "first" demyelinating event.. Journal of Neurology, Neurosurgery and Psychiatry, 2010, 82 (3), pp.323. 10.1136/jnnp.2008.166421 . hal00594138

\section{HAL Id: hal-00594138 \\ https://hal.science/hal-00594138}

Submitted on 19 May 2011

HAL is a multi-disciplinary open access archive for the deposit and dissemination of scientific research documents, whether they are published or not. The documents may come from teaching and research institutions in France or abroad, or from public or private research centers.
L'archive ouverte pluridisciplinaire HAL, est destinée au dépôt et à la diffusion de documents scientifiques de niveau recherche, publiés ou non, émanant des établissements d'enseignement et de recherche français ou étrangers, des laboratoires publics ou privés. 


\section{Title page}

Word counts for the abstract: 247

Word counts for the text: 1511

Character count for the title: 83

Title: Prior suggestive symptoms in one-third of patients consulting for a 'first' demyelinating event

Authors: O. Gout ${ }^{1}$, MD; C. Lebrun Frenay ${ }^{2}$, MD; P. Labauge ${ }^{3}$, MD, PhD; G. E. LePage ${ }^{4}$, MD; P. Clavelou ${ }^{5}, \mathrm{MD}, \mathrm{PhD} ; \mathrm{S}$. Allouche ${ }^{6}$, MD and PEDIAS* Group *PEDIAS = Premier Evènement Démyélinisant Inflammatoire et Antécédents Suggestifs (First Inflammatory Demyelinating Event and Suggestive Antecedents) Affiliations: ${ }^{1}$ Fondation A. de Rothschild - Paris; ${ }^{2}$ Hôpital Pasteur - Nice; ${ }^{3}$ GHU Caremeau - Nimes; ${ }^{4}$ Hôpital Pontchaillou - Rennes ; ${ }^{5}$ CHU G. Montpied - Clermont-Ferrand; ${ }^{6}$ Teva Pharma - Paris-La Défense

Supplemental data: E-Table 1: EDSS scores for all patients E-Table 2: Sample of PEDIAS questionnaire Author receiving correspondence: Olivier Gout, MD, Service de Neurologie, Fondation Ophtalmologique Adolphe de Rothschild, Paris

Disclosure of any personal or financial support:

The authors report no conflicts of interest, except for S. Allouche. 
"The Corresponding Author has the right to grant on behalf of all authors and does grant on behalf of all authors, an exclusive licence (or non exclusive for government employees) on a worldwide basis to the BMJ Publishing Group Ltd and its Licensees to permit this article (if accepted) to be published in the Journal of Neurology, Neurosurgery \& Psychiatry editions and any other BMJPGL products to exploit all subsidiary rights, as set out in our licence (http://jnnp.bmjjournals.com/ifora/licence.pdf)." 
Gout, $\mathrm{O}$ - page $3 / 14$

\section{ABSTRACT}

Objective: To evaluate the prevalence of prior inflammatory events in patients consulting for a first inflammatory neurological event, and improve early diagnosis of multiple sclerosis.

Methods: During the initial visit, the neurologist gave patients a self-administered questionnaire containing 72 questions regarding previous symptoms lasting more than 24 hours. During the follow-up visit the neurologist validated the symptoms and collected information about the current attack.

Results: The cohort included 178 patients (74\% women, mean age $( \pm \mathrm{SD}) 33.7( \pm 10.1)$ years). The main reason for the initial visit was visual disturbance and sensory troubles in limbs. Mean $( \pm \mathrm{SD})$ global EDSS score was $1.4( \pm 1.1), 46 \%$ of brains MRIs were positive according to Barkhof-Tintoré criteria, $41 \%$ had abnormal WBC count in CSF and $71 \%$ had IgG oligoclonal bands. Prior symptoms suggestive of demyelination were reported by 79 patients (44\%), validated by the neurologist for $70 \%$ (55 patients) and identified only by the neurologist in four patients. Sequelae were observed in 14 patients with validated prior symptoms (26\%). The self-administered questionnaire showed an overall sensitivity of $93 \%$ and specificity of $80 \%$ for identifying patients with prior symptoms suggestive of demyelination.

Conclusion: A patient-administered questionnaire subsequently validated by the neurologist demonstrated that $33 \%$ of patients consulting for a first demyelinating event had prior symptoms suggestive of CNS demyelination that had gone unnoticed, and almost $70 \%$ had either sequelae of prior demyelination or McDonald criteria for dissemination in space. Such a questionnaire could be a useful tool for earlier diagnosis of multiple sclerosis. 
Gout, O - page $4 / 14$

\section{Key words (Search Terms)}

Multiple sclerosis [41], clinical trial observational study [23], all demyelinating disease (CNS) [40], 
Gout, $\mathrm{O}$ - page $5 / 14$

\section{INTRODUCTION}

In multiple sclerosis (MS) the notion of first attack is still vague. Before the clinical event that leads to consultation in a hospital's Neurology department, there are often preexisting symptoms suggestive of MS such as fatigue, limb weakness, blurred vision, paresthesias, vertigo, and urinary disturbances[1]. These initial symptoms correspond to the Clinically Isolated Syndrome (CIS). In the study Optic Neuritis Treatment Trial (ONTT) [2, 3] antecedents such as those described above (mostly paresthesia) were identified in 45 of 149 (30\%) patients who had abnormal cerebral Magnetic Resonance Imaging (MRI) and 12 of $202(5.9 \%)$ patients with normal MRI. For all patients, whatever the MRI result, presence of such an antecedent was a risk factor for developing clinically definite MS within 5 years. Furthermore, according to McDonald's new criteria for MS diagnosis, [4, 5] patients who presented at the first attack with sequelae of a preexisting symptom suggestive of a demyelinating event (i.e., lasting at least for 24 hours), can be considered as having MS, as can patients who have had 2 attacks in addition to clinical evidence of one lesion and criteria for dissemination in space, which is demonstrated by MRI or at least 2T2 lesions and a positive cerebrospinal fluid (CSF). Therefore, the primary objective of the present study was to evaluate the prevalence of patients presenting with antecedents suggestive of demyelinating event(s) that went unnoticed among patients consulting or hospitalised in a Neurology department for a first inflammatory demyelinating event and to initiate the development of a specific screening questionnaire to accurately identify these suggestive antecedents.

\section{METHODS}

\section{Patients}


Gout, O - page 6/14

Patients included in the study were male and female adults who had been hospitalised or seen in the Neurology outpatient clinics for a first inflammatory neurological event.

\section{Study design}

This was a prospective, multicenter, observational pilot study, conducted in 14 French reference hospital neurology departments specialising in MS. The objective was to collect data on neurological antecedents in patients hospitalised for a first demyelinating event (i.e., CIS) as well as data on environmental factors and family history that could affect the management and evolution of the disease. Patients were included in the study after being informed about the study by the neurologist. At the initial visit, the neurologist gave a selfadministered questionnaire to patients about antecedents suggestive of a first demyelinating event. Patients were invited to fill out the questionnaire at home and to return it at the next planned visit. Questions were about demographic data (age, sex, marital status), sociogeographic characteristics (occupation, educational level, residence area), and neurologically relevant medical and family history. In particular, the patient had to describe all previous symptoms lasting more than 24 hours that could be related to a CNS demyelination: fatigue, visual disturbance (diplopia, blurred vision, and ocular pain), sensations (tingling, burning, numbness, electrical shock in one or several limbs), clumsiness (hand clumsiness, impaired walking, and limb muscle weakness), bladder problems (urinary urgency or retention), loss of balance, vertigo, hearing disturbance, and facial paralysis. During the normal follow-up visit (usually one to two months after the initial visit), the patient returned the completed questionnaire to the neurologist, who then reviewed it with the patient. The neurologist then completed part of the questionnaire, indicating: onset of the current attack, supposed localisation of the neurological lesion, Expanded Disability Status Scale (EDSS) score, [6] and signs and symptoms attesting to the antecedents reported by the patient. The neurologist also reported all available results of complementary tests concerning this current attack, 
including brain MRI, Barkhof-Tintoré criteria[7, 8] evaluation, and lumbar puncture. All brain MRI was performed on 1.5-Tesla scanner and IgG oligoclonal bands were detected by isoelectric focusing.

\section{Statistical methods}

Descriptive statistics were performed for all patients or events, and for selected sub-groups. For quantitative variables, the total number, mean, standard deviation (SD), median, quartiles, and range were calculated. For qualitative data, the total number, percentages, and $95 \%$ Confidence Interval were calculated. Comparisons between groups $\left(\mathrm{Chi}^{2}\right.$, Fisher and Wilcoxon tests) and correlations were performed considering $\alpha$ risk at level 5\%. An analysis of sensitivity and specificity was performed on the questionnaire.

\section{RESULTS}

\section{Population description}

A total of 178 patients were included: 131 women $(74 \%)$ and 47 men $(26 \%)$. Mean $( \pm$ SD) age at baseline was $33.7( \pm 10.1)$ years, with a range of $15-60$ years. A family history of MS was reported by $11 \%$ of the patients. Most patients (72\%) were referred by a specialist, usually an ophthalmologist, neurologist, or emergency department physician. The median time between the first episode and the patient's initial visit was 29 days (range, 0-686 days). According to the neurologist, the affected area of the CNS was the optical nerve (in 33\% of cases), spinal cord $(37.5 \%)$, brainstem $(12.5 \%)$, or brain $(11 \%)$. Six percent of patients presented with two different affected sites. Mean EDSS score was $1.4( \pm 1.1)$.

\section{Brain MRI results}

MRI was performed for $99 \%$ of the patients, and with gadolinium infusion for $94 \%$ of patients. The mean delay from onset was $27( \pm 24)$ days (range, 0-87 days). MRI was 
Gout, $\mathrm{O}$ - page $8 / 14$

abnormal in $87 \%$ of cases and $46 \%$ were positive according to Barkhof-Tintoré criteria (presenting with at least 3 of the 4 criteria).

\section{Lumbar puncture - Cerebrospinal fluid (CSF) test}

Lumbar puncture was performed for $87.5 \%$ of the patients. The mean white blood cell (WBC) count was 7 cells $/ \mathrm{mm}^{3}$ (range 0-100). Immunoglobin G (IgG) oligoclonal bands were present in $71 \%$ of patients.

\section{Prior symptoms suggestive of demyelination}

A total of 139 prior symptoms suggestive of demyelination were reported by 79 patients (44\%), and at least one of these suggestive symptoms was validated by the neurologist for 55 patients (70\%) (fig 1). In addition, neurologists identified 12 prior symptoms in 10 patients that had not been reported by the patients. Therefore, neurologists identified 59 patients (33\%) with at least one prior symptom suggestive of demyelination: 36 patients presented with a single event and 23 patients presented with several events, usually two or three. The mean time period between the first suggestive symptom and the first demyelinating event leading to a Neurology department consult was 46 months (range, 1 to 202 months). The most frequent events were tingling sensations (9.6\% of all patients), visual disturbances $(6.2 \%)$ and muscular weakness in one or several limbs (6.2\%). Partial numbness, impaired walking, and loss of balance were each suggestive of prior CNS demyelination for 9 patients $(5.1 \%)$. Six to eight patients presented with electrical shock sensation (Lhermitte's sign), diplopia, fatigue, or urinary urgency. Most demyelinating events led to consultation with a general practitioner (GP) or a specialist (or both, for 26 patients) but no further investigation had been performed to diagnose CNS demyelination. In summary, in terms of identifying patients with at least one prior symptom suggestive of demyelination, the self-administered questionnaire had an overall sensitivity of $93 \%$ and specificity of $80 \%$ (table 1). Sensitivity was then analyzed for each symptom reported by the patient or identified by the neurologist. Sensitivity was 
Gout, O - page $9 / 14$

excellent but the rate of false positives was high for vertigo (77\%), hearing disturbance (75\%), bladder problems (63\%), and fatigue (58\%). Conversely, positive predictive value was good (over 70\%) for facial paralysis, sensation, and visual disturbance. Comparison of MRI findings with the presence or absence of prior symptoms suggestive of demyelination showed that abnormal MRI was more frequent in patients with prior symptoms $(95 \%$ compared to $84 \%, \mathrm{p}=0.039)$.

Sequelae attesting to prior demyelinating events were reported for 14 patients (8\% of all patients and $26 \%$ of patients reporting validated prior symptoms). Finally, according to McDonald criteria, 70\% of patients with prior symptoms had MS (fig 1).

\section{DISCUSSION}

New MS diagnosis criteria based on MRI findings[9] have good sensitivity and specificity.[10-13] In this pilot study, paraclinical results were taken into account to standardise diagnosis of a first event of inflammatory demyelination. In addition, a selfadministered questionnaire was tested to identify previous neurological inflammatory events suggestive of MS and possible sequelae present at examination in order to fulfil criteria for MS. Characteristics of the cohort of patients included in this study were consistent with those previously described for patients with inflammatory demyelinating disease.

Neurologists could identify previous relevant events suggestive of CNS demyelination in $33 \%$ of patients coming to the neurology department for a perceived initial inflammatory demyelinating event. Half of these patients had even reported several suggestive prior symptoms. There was an average interval of 46 months between these antecedents and the current episode leading to neurology department consult. Interesting findings were that most of these previous events led patients to visit a GP, a specialist, or both, but did not lead to further investigation and special follow-up. The self-administered questionnaire was revealed 
to be a useful tool with which to identify patients with prior symptoms suggestive of demyelination. Reported prior symptoms were validated by a neurologist for $70 \%$ of patients. Neurologists identified only four more patients with suggestive prior symptoms that were not reported in the self-administered questionnaire. Finally, symptoms or signs at examination attesting to these prior demyelinating events were reported for $24 \%$ of patients and criteria for dissemination in space were fulfilled in another $46 \%$, leading to a diagnosis of MS in $70 \%$ of these patients.

\section{ACKNOWLEDGMENTS}

This study was sponsored by Foundation Rothschild and received financial support from Teva Pharmaceuticals and Sanofi Aventis.

Thanks to the members of the PEDIAS Group: Heinzlef O., CHI Poissy/St Germain - Poissy; Roullet E., Hôpital Tenon - Paris; Hautecoeur P., CH St Philibert - Lomme; De Seze J., CHU de Strasbourg, Hôpital civil - Strasbourg; Camu W., Hôpital G. de Chauliac Montpellier; Defer G., CHU Côte de Nacre - Caen; Pelletier J., CHU La Timone Marseille; Debouverie M., Hôpital Central - Nancy; Barroso B.,, Hôpital F. Mitterrand Pau; Coustans M., Centre hospitalier de Cornouaille - Quimper; Laplaud D., Hôpital Laënnec - Nantes; Rumbach L., Hopital J. Minjoz - Besançon; Lyon-caen O., Tourbah A., Hôpital de la Pitié-Salpétrière - Paris; Lebiez P.E., CH Louis Pasteur - Cherbourg; Moreau T., CHU Dijon - Dijon; Magy L., CHU Dupuytren - Limoges. 
Gout, O - page 11/14

\section{REFERENCES}

1. Compston A, Coles A. Multiple sclerosis. Lancet 2002;359:1221-31.

2. Optic Neuritis Study Group. The 5-year risk of MS after optic neuritis. Experience of the optic neuritis treatment trial. Neurology 2001;57:S36-45.

3. Optic Neuritis Study Group. High- and Low-risk profiles for the development of multiple sclerosis within 10 years after optic neuritis: experience of the optic neuritis treatment trial. Arch Ophtalmol 2003;121:1039-40.

4. McDonald WI, Compston A, Edan G, et al. Recommended diagnostic criteria for multiple sclerosis: guidelines from the international panel on the diagnosis of multiple sclerosis. Ann Neurol 2001;50:121-7.

5. Polman CH, Reingold SC, Edan G, et al. Diagnostic criteria for multiple sclerosis: 2005 revisions to the "McDonald Criteria". Ann Neurol 2005;58:840-6.

6. Kurtzke JF. Rating neurologic impairment in multiple sclerosis: an expanded disability status scale (EDSS). Neurology 1983;33:1444-52.

7. Barkhof F, Filippi M, Miller DH, et al. Comparison of MRI criteria at first presentation to predict conversion to clinically definite multiple sclerosis. Brain 1997;120:2059-69.

8. Tintoré M, Rovira A, Martínez MJ, et al. Isolated demyelinating syndromes: comparison of different MR imaging criteria to predict conversion to clinically definite multiple sclerosis. Am J Neuroradiol. 2000;21:702-706.

9. Tintoré M, Rovira A, Río J, et al. New diagnostic criteria for multiple sclerosis: application in first demyelinating episode. Neurology 2003;60:27-30.

10. Dalton CM, Brex PA, Miszkiel KA, et al. Application of the new McDonald criteria to patients with clinically isolated syndromes suggestive of multiple sclerosis. Ann Neurol 2002;52:47-53. 
11. Miller D, Barkhof F, Montalban X, Thompson A, Filippi M. Clinically isolated syndromes suggestive of multiple sclerosis, part I: natural history, pathogenesis, diagnosis, and prognosis. Lancet Neurol 2005;4:281-8.

12. Korteweg T, Tintoré $M$, Uitdehaag $B$, et al. MRI criteria for dissemination in space in patients with clinically isolated syndromes: a multicentre follow-up study. Lancet Neurol 2006;5:221-7.

13. Tintore M, Rovira A, Rio J, Nos C, Grive E, Tellez N, Pelayo R, Comabella M, SastreGarriga J, Montalban X. Baseline MRI predicts future attacks and disability in clinically isolated syndromes. Neurology 2006;67:968-72. 
Figure 1 Flow chart

178 patients with a «first demyelinating event» completed the self-administered questionnaire

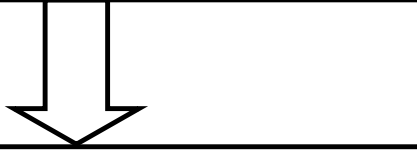

139 prior events reported by 79 Patients

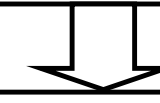

58 prior events not validated

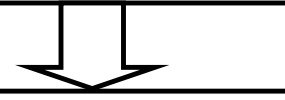

81 neurologist-validated prior events in 55 patients
119 patients had CIS

(68 had either MRI

dissemination in space

or $2 \mathrm{~T} 2$ lesion and

IgGOB)

68 had possible MS

and 51 had CIS

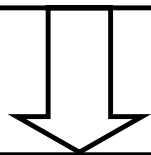

12 prior events, not reported by patients, were identified by neurologists in 10 patients

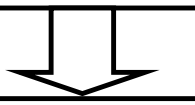

6 prior events in 4 new patients

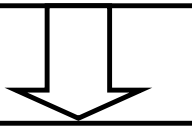

59 patients had prior events validated or identified by a neurologist

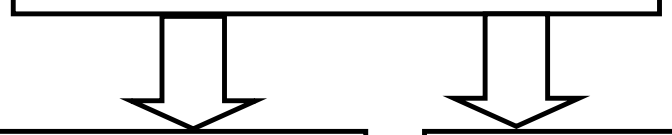

14 patients had sequelae of prior events (MS patients)
45 patients

(27 had either MRI dissemination in space or 2T2 lesion and IgGOB)

27 had MS and 28 had possible MS 
Table 1 Sensitivity and specificity of the self-administered questionnaire (Analysis in terms of patients)

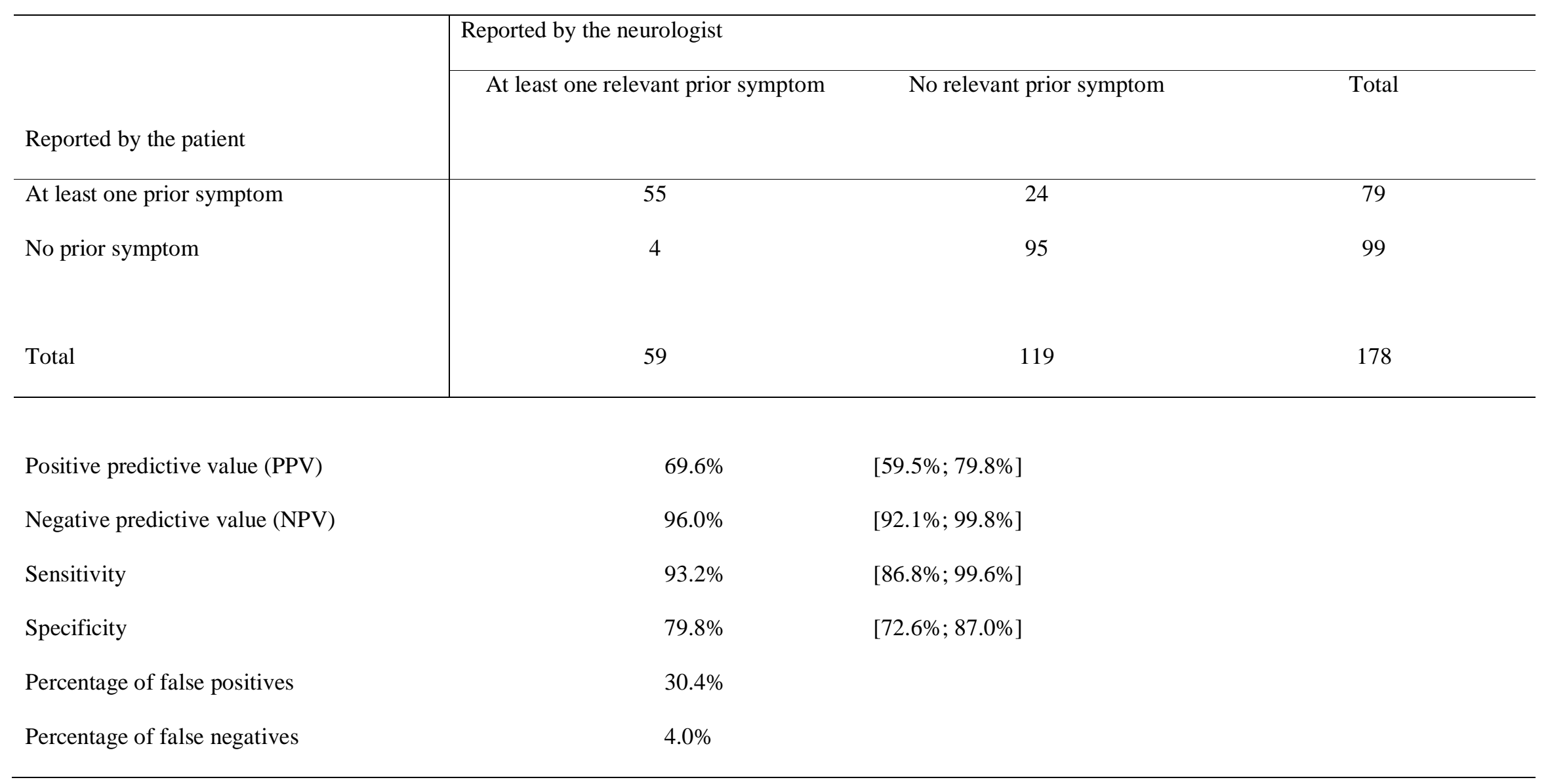

